J. Egypt. Soc. Parasitol. (JESP), 51(1), 2021: 17 - 22

(Online: 2090-2549)

\title{
PREVALENCE AND ASSOCIATED RISK FACTORS OF CYCLOSPORA CAYETANENSIS AND CYSTOISOSPORA BELLI INFECTIONS AMONG ADULT IMMUNE-COMPETENT PATIENTS WITH DIARRHEA ATTENDING MINIA UNIVERSITY HOSPITALS, EGYPT
} By

\author{
AZZA K. AHMED ${ }^{1}$, MANAR M. SANADEKI ${ }^{1}$, REHAM A. M. ABD RABOU ${ }^{1}$ AMANY \\ M. KAMAL ${ }^{1 *}$, WAEL M. ABDEL-GHANY ${ }^{2}$ AND MARWA G. ABDELREHIM ${ }^{3}$ \\ Department of Medical Parasitology ${ }^{1}$, Department of Tropical Medicine and \\ Gastroenterology ${ }^{2}$, and Department of Public Health and Preventive Medicine ${ }^{3}$, \\ Faculty of Medicine, Minia University, Minia, 61519, Egypt \\ ( ${ }^{*}$ Correspondence: AmanyKamal20002000@yahoo.com)

\section{Abstract}

The prevalence of emerging human intestinal protozoan pathogens in immune-competent adults was not clearly determined in Egypt. This study assessed the prevalence of Cyclospora cayetanensis and Cystoisospora belli and their associated risk factors in Minia Governorate, Egypt. Fecal samples were collected from 190 immunocompetent patients suffering from diarrhea with or without other gastrointestinal manifestations, from June 2018 to February 2019. Questionnaires for demographic and clinical data were filled out for each patient. Fecal samples were examined macroscopically and microscopically followed by modified Ziehl-Neelsen stain to identify oocysts Cyclospora cayetanensis and Cystoisospora belli. 113 patients (59.5\% with 95\% CI, 52.5-66.5) out of 190 patients were infected with Cryptosporidium spp., Blastocystis spp., Entamoeba histolytica/dispar, Giardia intestinalis, Cyclospora cayetanensis, and Cystoisospora belli. Co-infection was detected in 22 cases (11.6\%) and single parasitic infection was detected in 91cases (47.9\%). Cyclospora cayetanensis was reported in 19 cases (10\%) While, Cystoisospora belli was detected in 3 cases (1.7\%). Cyclospora cayetanensis and Cystoisospora belli infections were significantly associated watery diarrhea and higher consumption of unwashed fruit or vegetable with no role for animal contact in their transmission. The study result implicated that $C$. cayetanensis is an important cause of adult diarrhea.

Keywords: Egypt, patients, Cyclospora, Cystoisospora, Cryptosporidium, Blastocystis, Diarrhea.

\section{Introduction}

Coccidia of genus Cyclospora and genus Cystoisospora (previously Isospora) are obligate intracellular apicomplexan parasites that parasitize the gastrointestinal tract of humans and animals causing diarrhea diseases. Although, they were initially recognized as opportunistic parasites in immunecompromised patients, they were also associated with sporadic and endemic disease in immune-competent patients (Legua and Seas, 2013). Human Cyclospriasis and Cystoisosporasis are caused by tcoccidian species Cyclospora cayetanensis and Cystoisospora belli respectively (Legua and Seas, 2013).

Human infection occurs by ingestion of food or water contaminated with sporulated oocysts. Man to man transmission was not reported as the excreted oocysts required 1 to 2 weeks in environment to become infective (Escobedo et al, 2009).
Clinical presentations mainly depended on host age and immune status. Asymptomatic or mild infections occur in older children and non-elderly adults. Severe clinical symptoms occur in infants and elderly persons. Mild-to-moderate self-limiting diarrhea is common in immune-competent patients. Patients with immune dysfunction can experience severe disease with prolonged diarrhea, anorexia, and weight loss (Almeria et al, 2019; Dubey and Almeria, 2019).

Microscopy using acid-fast staining is the most widely used screening technique for the diagnosis of $C$. cayetanensis and $C$. belli with or without stool concentration (Ribes et $a l, 2004)$. In wet mount smears, $C$. cayetanensis oocyst is spherical in shape and bet ween $7.5 \& 10 \mu \mathrm{m}$ in diameter, while $C$. belli oocyst is ovoid to ellipsoid in shape, 10-40 $\mu \mathrm{m} \times 10-30 \mu \mathrm{m}$ with only one or two immature sporoblasts. Modified Ziehl-Neelsen sta- 
in technique was the gold standard, C. cayetanensis oocysts were stained pink to red color against green (blue) background color, while $C$. belli oocysts are stained red (Khanna et al, 2014).

PCR gave a limited role for detecting $C$. cayetanensis and $C$. belli in human feces due to high cost (Taniuchi et al, 2011) despite its high diagnostic sensitivity. However, no serological assays are commercially available for these parasites (Almeria et al, 2019; Dubey and Almeria, 2019).

Although, previous studies documented the presence of $C$. cayetanensis and $C$. belli in Egypt (Abdel-Hafeez et al, 2012; Massoud et al, 2012; Shehata and Hassanein, 2015; Ismail and Fadl, 2019), there was limited scientific data regarding the prevalence of these_parasites among adult diarrheic patients.

The present study aimed to assess prevalence and associated risk factors of $C$. cayetanensis and $C$. belli in immune-competent adult patients with diarrhea attended Tropical Medicine and Gastroenterology Outpatient Clinic of Minia University Hospitals.

\section{Material and Methods}

This cross-sectional descriptive study was done on 190 patients, referred to Tropical Medicine and Gastroenterology Outpatient Clinic of Minia University Hospitals from June 2018 to February 2019. All patients were suffered from diarrhea with or without other gastro-intestinal disturbances. Immu ne-compromised patients or patients with diarrhea due to other causes or those on antiparasitic medications 2 weeks before study were excluded. A structured questionnaire concerning required demographic and clinical data was filled out for each studied case.

Stool examinations: Single fecal sample from each participant was collected in sterile, labeled, plastic containers with tightfitting covers, and transported to the Parasitology Department, Faculty of Medicine, Minia University within 1-3h after collection. The samples were examined following standard procedures (WHO, 2012). The sto- ol samples were initially examined macroscopically and their characteristics such as color and consistency were recorded. Samples were processed by direct wet smear and formalin-ethyl-acetate sedimentation methods for ova and other stages (Cheesbrough, 2009). To identify oocysts of C. cayetanensis and C. belli, a permanent slide was prepared for each sample, stained with Modified Ziehl-Neelsen acid fast technique. Following fixation with methanol for $5 \mathrm{~min}$, the primary stain (carbon fuchsine) was applied for $10 \mathrm{~min}$. The smear was washed and decolorized with $1 \%$ acid alcohol. The counter stain $(0.5 \%$ malachite green) was then applied for $30 \mathrm{~min}$. The smear was washed off, dried, and examined accordingly (Garcia, 2016). Stained smears were microscopically examined with the high power and oil immersion objective.

Ethical approval: The study protocols and the consent forms were reviewed and approved by the Scientific Ethical Committee of Faculty of Medicine, Minia University on April 2018. All participants provided written informed consent after the study procedures were explained.

Statistical analysis: Data were entered in MS Excel version 2007 \& analyzed using SPSS 24.0 software. Numbers, percentages $\&$ mean SD were calculated. Fisher's exact test compared proportions. Multivariate Binary Logistic Regression determined associated risk factors of $C$. cayetanensis and $C$. belli infection with significance at $\mathrm{p}<0.05$.

\section{Results}

A total of 190 patients with diarrhea were investigated to assess the prevalence of $C$. cayetanensis and $C$. belli. The mean age of the participants was $33.6 \pm 4.8$ years, ranging 20-67 years. Most participants were males $(117,61.6 \%)$, and the majority come from rural areas $(126,66.3 \%)$. Frequent reported clinical manifestations associated with diarrhea were abdominal pain followed by vomiting where they were reported in $86.3 \%$ and $61.5 \%$ of total patients, respectively. The total prevalence rate of intestinal parasitic 
infections in the present study was $59.5 \%$ $(113 / 190)$ (95\% CI, 52.5-66.5). The infection rates of male and female patients were $61.5 \%(72 / 117)$ and $56.2 \%(41 / 73)$.

Two or more parasites infection were $22 /$ $190(11.6 \%)$, but $91 / 190(47.9 \%)$ with a single parasite. C. cayetanensis was 19/190 $(10 \%)$ those with C. cayetanensis, Cryptosporidium spp. coinfection was 3/19 (15.8\%), $\&$ C. cayetanensis, E. histolytica/dispar 1/19 (5.2\%). C. belli was 1.6\% (3/190) with Blastocystis spp. co-infected in two of them. Cryptosporidium sp., Blastocystis sp., E. hit- tolytica/dispar, $G$. intestinalis and $E$. coli were $27.4 \%, 17.9 \%, 7.4 \%, 6.3 \%, 1.6 \%$ respectively. Clinical features were not significantly associated with $C$. cayetanensis or $C$. belli except for diarrhea. C. cayetanensis or C. belli patients had watery diarrhea $(87.5 \%)$ than negative patients $(50.6 \%)$.

C. cayetanensis or C. belli was significantly associated with low probability of animal contact and higher consumption of unwashed fruit or vegetables.

Details were given in tables $(1,2, \& 3)$ and figures $1 \& 2$ ).

Table 1: Distribution of single and mixed intestinal parasitic infections among patients with diarrhea.

\begin{tabular}{|c|c|c|}
\hline Type of infection & Intestinal parasites & Number \& (\%) \\
\hline \multirow[t]{7}{*}{ Single infection } & Cryptosporidium spp. & $37(19.5)$ \\
\hline & Blastocystis spp. & $20(10.5)$ \\
\hline & Entamoeba histolytica/dispar & $10(5.2)$ \\
\hline & Giardia intestinalis & $8(4.2)$ \\
\hline & Cyclospora cayetanensis & $15(7.9)$ \\
\hline & Cystoisospora belli & $1(0.5)$ \\
\hline & & $91(47.9)$ \\
\hline \multirow[t]{12}{*}{ Mixed infection } & Cyclospora cayetanensis + Cryptosporidium spp. & $3(1.6)$ \\
\hline & Cyclospora cayetanensis + Entamoeba histolytica /dispar & $1(0.5)$ \\
\hline & Cryptosporidium spp. + Blastocystis spp. & $6(3.2)$ \\
\hline & Cryptosporidium spp. + Giardia intestinalis & $2(1.1)$ \\
\hline & Cryptosporidium spp.+ Entamoeba coli & $2(1.1)$ \\
\hline & Blastocystis spp. + Entamoeba histolytica/dispar & $2(1.1)$ \\
\hline & Blastocystis spp. + Cystoisospora belli & $2(1.1)$ \\
\hline & Blastocystis spp. + Giardia intestinalis & $1(0.5)$ \\
\hline & Blastocystis spp. + Entamoeba coli & $1(0.5)$ \\
\hline & Cryptosporidium spp.+ Blastocystis spp.+ Giardia intestinalis & $1(0.5)$ \\
\hline & Cryptosporidium spp. + Blastocystis spp. + Entamoeba histolytica/dispar & $1(0.5)$ \\
\hline & & $22(11.6)$ \\
\hline
\end{tabular}

Table 2: Relation between C. cayetanensis or C. belli infection and clinical presentations among patients with diarrhea.

\begin{tabular}{|c|l|c|c|c|}
\hline Clinical presentations & $\begin{array}{l}\text { Total patients } \\
(\mathrm{n}=1840\end{array}$ & $\begin{array}{c}\text { C. cayetanensis or C. } \text { belli }^{\mathrm{a}} \\
\text { Positive }(\mathrm{n}=16)\end{array}$ & $\begin{array}{c}\text { C. cayetanensis \& C. } \text { belli }^{b} \\
\text { Negative }(\mathrm{n}=168)\end{array}$ & P value $^{\mathrm{c}}$ \\
\hline Abdominal pain: Yes & $160(87 \%)$ & $12(75 \%)$ & $148(88.1 \%)$ & \\
No & $24(13 \%)$ & $4(25 \%)$ & $20(11.9 \%)$ & 0.233 \\
\hline Nausea: Yes & $83(45.1 \%)$ & $9(56.3 \%)$ & $74(44 \%)$ & \\
No & $101(54.9 \%)$ & $7(43.7 \%)$ & $94(56 \%)$ & 0.433 \\
\hline Vomiting: Yes & $113(61.4 \%)$ & $10(62.5 \%)$ & $103(61.3 \%)$ & \\
No & $71(38.6 \%)$ & $6(37.5 \%)$ & $65(38.7 \%)$ & 0.928 \\
\hline Fever: Yes & $95(51.6 \%)$ & $5(31.3 \%)$ & $90(53.6 \%)$ & \\
No & $89(48.4 \%)$ & $11(68.8 \%)$ & $78(46.4 \%)$ & 0.074 \\
\hline Diarrhea: Watery & $99(53.8 \%)$ & $14(87.5 \%)$ & $85(50.6 \%)$ & \\
Semi-formed & $85(46.2 \%)$ & $2(12.5 \%)$ & $83(49.4 \%)$ & 0.007 \\
\hline
\end{tabular}

${ }^{a}$ Patients with single C. cayetanensis or C. belli only included, ${ }^{b}$ Cases with C. cayetanensis or C. belli and other intestinal parasites excluded, ${ }^{\mathrm{c}} \mathrm{P}$-value by Fisher's Exact test

\section{Discussion}

Despite substantial global effort and programs organized by the World Health Organization (WHO), intestinal parasitic infections are among the most important causes of morbidity and mortality, particularly in developing countries and one of the most important etiologies of diarrheal diseases (Berhe et al, 2018). Since C. cayetanensis and $C$. belli caused diarrheal disease in immune-competent and immune-suppressed patients worldwide (Ciçek et al, 2011; Ud Din et al, 2011), this cross-sectional descriptive study was performed to provide more 
informative epidemiological data about the two parasites in Minia Governorate.

Table 3: Risk factors of $C$. cayetanensis or C. belli among patients with diarrhea.

\begin{tabular}{|c|c|c|c|c|c|}
\hline Risk factors & $\begin{array}{l}\text { Total patients } \\
(\mathrm{n}=184) \\
\text { No. }(\%)\end{array}$ & $\begin{array}{l}\text { Positive } \\
\text { C. cayetanensis } \\
\text { or } C . \text { belli }^{\text {a }}(\mathrm{n}=16)\end{array}$ & $\begin{array}{l}\text { Negative } \\
\text { C. } \text { cayetanensis \& } C \text {. } \text { belli }{ }^{\mathrm{b}}(\mathrm{n}=168)\end{array}$ & $\begin{array}{l}\text { OR } \\
(95 \% \mathrm{CI})^{\mathrm{c}}\end{array}$ & $\begin{array}{l}\text { P } \\
\text { value }^{\mathrm{d}}\end{array}$ \\
\hline $\begin{array}{l}\text { Male } \\
\text { Female }\end{array}$ & $\begin{array}{l}115(62.5) \\
69(37.5)\end{array}$ & $\begin{array}{l}11(68.8 \%) \\
5(31.2 \%)\end{array}$ & $\begin{array}{l}104(61.9 \%) \\
64(38.1 \%)\end{array}$ & $1.09(0.33-3.64)$ & 0.886 \\
\hline $\begin{array}{l}20-35(\text { years }) \\
36-50(\text { years }) \\
>50(\text { years })\end{array}$ & $\begin{array}{l}84(45.7) \\
57(31) \\
43(23.3) \\
\end{array}$ & $\begin{array}{l}6(37.5 \%) \\
4(25 \%) \\
6(37.5 \%)\end{array}$ & $\begin{array}{l}78(46.5 \%) \\
53(31.5 \%) \\
37(22 \%) \\
\end{array}$ & $\begin{array}{l}0.58(0.15-2.19) \\
0.50(0.12-2.14)\end{array}$ & $\begin{array}{l}0.424 \\
0.351\end{array}$ \\
\hline $\begin{array}{r}\text { Residence: Rural } \\
\text { Urban }\end{array}$ & $\begin{array}{l}123(66.8) \\
61(33.2)\end{array}$ & $\begin{array}{l}11(68.8 \%) \\
5(31.2 \%)\end{array}$ & $\begin{array}{l}112(66.7 \%) \\
56(33.3 \%)\end{array}$ & $2.69(0.53-13.71)$ & 0.234 \\
\hline $\begin{array}{r}\text { Animal contact: Yes } \\
\text { No }\end{array}$ & $\begin{array}{l}119(64.7) \\
65(35.3)\end{array}$ & $\begin{array}{l}8(50 \%) \\
8(50 \%) \\
\end{array}$ & $\begin{array}{l}111(66.1 \%) \\
57(33.9 \%)\end{array}$ & $0.12(0.02-0.61)$ & 0.011 \\
\hline $\begin{array}{r}\text { Raw fruits \& vegetables: Yes } \\
\text { No }\end{array}$ & $\begin{array}{l}89(48.4) \\
95(51.6)\end{array}$ & $\begin{array}{l}12(75 \%) \\
4(25 \%)\end{array}$ & $\begin{array}{l}77(45.8 \%) \\
91(54.2 \%)\end{array}$ & $7.16(1.77-28.94)$ & 0.001 \\
\hline
\end{tabular}

${ }^{\mathrm{a}}$ Patients with $C$. cayetanensis or $C$. belli only were included, ${ }^{\mathrm{b}}$ Double infection of $C$. cayetanensis or $C$. belli and other parasites were excluded, ${ }^{\mathrm{c}} \mathrm{OR}$ : Odd's ratio, CI: Confidence interval, ${ }^{\mathrm{d}} \mathrm{P}$-value of multivariate binary logistic regression.

Overall parasitic prevalence among immune-competent patients with diarrhea was 59.5\% (with 95\% CI, 52.5-66.5), this prevalence rate was like that reported by AbdelHafeez et al, (2012) in immune-competent children from the same governorate. The identified intestinal parasites from this study's participants were only protozoan parasites (Cryptosporidium spp., Blastocystis spp., Entamoeba histolytica/Dispar, Giardia intestinalis, Cyclospora cayetanensis, Cystoisospora belli and Entamoeba coli) and many papers from Egypt reported higher protozoan infections than helminthic infections with higher prevalence of Cryptosporidium spp. (Baiomy et al, 2010; Abdel-Hafeez et al, 2012). No helminthic infections were detected in this study might be due increase the awareness of helminthic infections transmission and regular mass treatment of anti-helminthic drugs in governmental schools (Dahesh, 2018).

Co-infection with two or more parasites was recognized in 22 patients, as these parasites almost have the same mode of transmission which is waterborne and foodborne routes. Waterborne protozoan diseases in Minia district were reported by Khalifa et al, (2014) especially Cryptosporidium spp. Blastocystis spp. or Cryptosporidium/C. cayetanensis.

C. cayetanensis and C. belli were detected in $10 \%$ and $1.6 \%$ of the participants of this study respectively, while in Minia district was $(2.1 \%)$ in children in 2012 (Abdel-Hafeez et al, 2012). Other papers from Egypt reported a prevalence rate of $C$. cayetanensis ranged from $17 \%$ to $19.6 \%$ in the immunecompetent children (Abdel-Wahab et al, 2008; Massoud et al, 2012). The prevalence rate of $C$. belli in Minia district was $6.3 \%$ in 2012 (Abdel-Hafeez et al, 2012). Reportable data on the prevalence of $C$. cayetanensis and $C$. belli in adult immune-competent were insufficient.

Patients with positive $C$. cayetanensis or C. belli more likely had watery diarrhea than negative patients $(\mathrm{P}=0.007)$. Several studies and human case reports stated $C$. cayetanensis and $C$. belli as a cause of watery diarrhea in immune-competent and immune-compromised patients (Ozdamar et al, 2010; Kim et al, 2013; Jiang et al, 2018; Almeria et al, 2019).

No significant association was between the prevalence of $C$. cayetanensis and $C$. belli and risk factors, including sex, age, residence, and animal contact. However, C. cayetanensis and $C$. belli infections were significantly associated with consumption of unwashed fruits and vegetables. This agrees with (Mahmoudvand et al, 2019). In addition, the meta-analysis studies done by Almeria et al, (2019); Li et al, (2019) and Dubey and Almeria (2019) confirmed this association. Furthermore, the C. cayetanensis and C. belli sporulated oocysts can remain in the environment for a longtime maintaining in- 
fectivity. This agreed with Li et al. (2020) who reported that $C$. cayetanensis and $C$. be$l l i$ were frequently recovered from raw vegetables.

\section{Conclusion}

Cryptosporidium spp., Blastocystis spp. and Cyclospora cayetanensis were prevalent among immunocompetent adult patients admitted to Minia University hospital. $C$. belli was infrequently detected in this study. Consumption of unwashed fruit or vegetable is a main route of $C$. cayetanensis and $C$. belli transmission.

\section{References}

Abdel-Hafeez, EH, Ahmad, AK, Ali, BA, Moslam, FA, 2012: Opportunistic parasites among immunosuppressed children in Minia District. Egypt. Korean J. Parasitol. 50: 57-62.

Abdel-Wahab, AM, El-Sharkawy, SG, Rayan, HZE, Hussein, EM, 2008: Detection of $C y$ clospora cayetanensis Infections among Diarrheal Children Attending Suez Canal University Hospital. P.U.J. 1: 37-46.

Almeria, S, Cinar, HN, Dubey, JP, 2019: $C y$ clospora cayetanensis and cyclosporiasis: an update. Microorganisms 7, 9:317-21.

Baiomy, AM, Mohamed, KA, Ghannam, MA, Shahat, SA, Al-Saadawy, AS, 2010: Opportunistic parasitic infections among immunocompromised Egyptian patients. J. Egypt Soc. Parasitol. 40, 3:797-808.

Berhe, B, Bugssa, G, Bayisa, S, Alemu, M, 2018: Foodborne intestinal protozoan infection and associated factors among patients with watery diarrhea in Northern Ethiopia; a cross- sectional study. J. Health. Popul. Nutr. 2, 37, 1:5-9.

Cheesbrough, M, 2009: District Laboratory Practice in Tropical Countries, Part 1. $2^{\text {nd }}$ Ed. New York: Cambridge University Press.

Ciçek, M, Uçmak, F, Ozekinci, T, 2011: $C y c$ lospora cayetanensis'in neden olduğu iki diyare olgusu (Two diarrhea cases caused by Cyclospora cayetanensis). Mikrobiyol. Bul. 45(3): 553-7.

Dahesh, SMA, 2018: Evaluation of a deworming campaign by albendazole during 2016 in a rural area of Giza Governorate, Egypt. P.U.J. 11: 52-61.

Dubey, JP, Almeria, S, 2019: Cystoisospora belli infections in humans: the past 100 years. Parasitology 146, 12:1490-527.

Escobedo, AA, Almiral, P, Alfonso, M, Cime- rman, S, Rey, S, et al, 2009: Treatment of intestinal protozoan infections in children. Arch. Dis. Child. 94, 6:478-82.

Garcia, SL, 2016: Diagnostic Medical Parasitology. $6^{\text {th }}$ Ed. ASM Press; Washington, USA.

Ismail, MAM, Fadl, HO, 2019: Cyclospora infection in renal transplant recipient. J. Egypt. Soc. Parasitol. 49, 3:727-30.

Jiang, Y, Yuan, Z, Zang, G, Li, D, Wang, Y, et al, 2018: Cyclospora cayetanensis infections among diarrheal outpatients in Shanghai: A retrospective case study. Front Med. 12, 1:98-103.

Khalifa, RMA, Ahmad, AK, Abdel-Hafeez, E H, Mosllem, FA, 2014: Present status of protozoan pathogens causing water-borne disease in northern part of El-Minia Governorate, Egypt. J. Egypt. Soc. Parasitol. 44, 3:559-66.

Khanna, V, Tilak, K, Ghosh, A, Mukhopadhyay, C, 2014: Modified negative staining of Heine for fast and inexpensive screening of Cryptosporidium, Cyclospora, and Cystoisospora spp. Int. Sch. Res. Notices 165424 online 2014 Oct 20 doi: 10.1155/2014/165424.

Kim, MJ, Kim, WH, Jung, HC, Chai, JW, Chai, JY, 2013: Isospora belli Infection with Chronic Diarrhea in an Alcoholic Patient. Korean. J. Parasitol. 51, 2:207-12.

Legua, P, Seas, C, 2013: Cystoisospora and $C y$ clospora. Curr. Opin. Infect. Dis. 26, 5:479-83.

Li, J, Wang, R, Chen, Y, Xiao, L, Zhang, L, 2019: Cyclospora cayetanensis infection in humans: biological characteristics, clinical features, epidemiology, detection method and treatment. Parasitology 147:1-11.

Li, J, Wang, Z, Karim, MR, Zhang, L, 2020: Detection of human intestinal protozoan parasites in vegetables and fruits: a review. Parasit Vect.13, 1:380-4.

Mahmoudvand, H, Sepahvand, A, Khatami, M, Moayyedkazemi, A, 2019: Prevalence and associated risk factors of Cystoisospora belli and Cyclospora cayetanensis infection among Iranian patients with colorectal cancer. J. Parasit. Dis. 43, 3:402-5.

Massoud, NM, Said, DE, El-Salamouny, AR, 2012: Prevalence of Cyclospora cayetanensis among symptomatic and asymptomatic immunecompetent children less than five years of age in Alexandria, Egypt. Alex. J. Med. 48:251-9.

Ozdamar, M, Hakko, E, Turkoglu, S, 2010: High occurrence of cyclosporiasis in Istanbul, Turkey, during a dry and warm summer. Parasit. Vect. 3:39-42. 
Ribes, JA, Seabolt, JP, Overman, SB, 2004: Point prevalence of Cryptosporidium, Cyclospo$\mathrm{ra}$, and Isospora infections in patients being evaluated for diarrhea. Am. J. Clin. Pathol. 122:28-32.

Shehata, AI, Hassanein, FI, 2015: Intestinal parasitic infections among mentally handicapped individuals in Alexandria, Egypt. Ann. Parasitol. 61:275-81.

Taniuchi, M, Verweij, JJ, Sethabutr, O, Bodhidatta, L, Garcia, L, et al, 2011: Multiplex polymerase chain reaction method to detect $C y$ - clospora, Cystoisospora and Microsporidia in stool samples. Diagn. Microbiol. Infect. Dis. 71, 4:386-90.

Ud Din, N, Torka, P, Hutchison, RE, Riddell, SW, Wright, JE, et al, 2012: Severe Isospora (Cystoisospora) belli diarrhea preceding the diagnosis of human T-cell-leukemia-virus-1associated T-Cell lymphoma. Case Rep. Infect. Dis. 2012:640104: Online 2012 Aug 16. Doi:10. $1155 / 2012 / 640104$

WHO, 2012: Bench aids for the diagnosis of intestinal parasites. Geneva, Switzerland.

\section{Explanation of figures}

Fig. 1: Frequency of intestinal parasites among adult patients with diarrhea.

Fig. 2: Cyclospora cayetanensis oocyst and Cystisopora belli oocyst in stools stained with Modified Ziehl-Neelsen stain, X100.
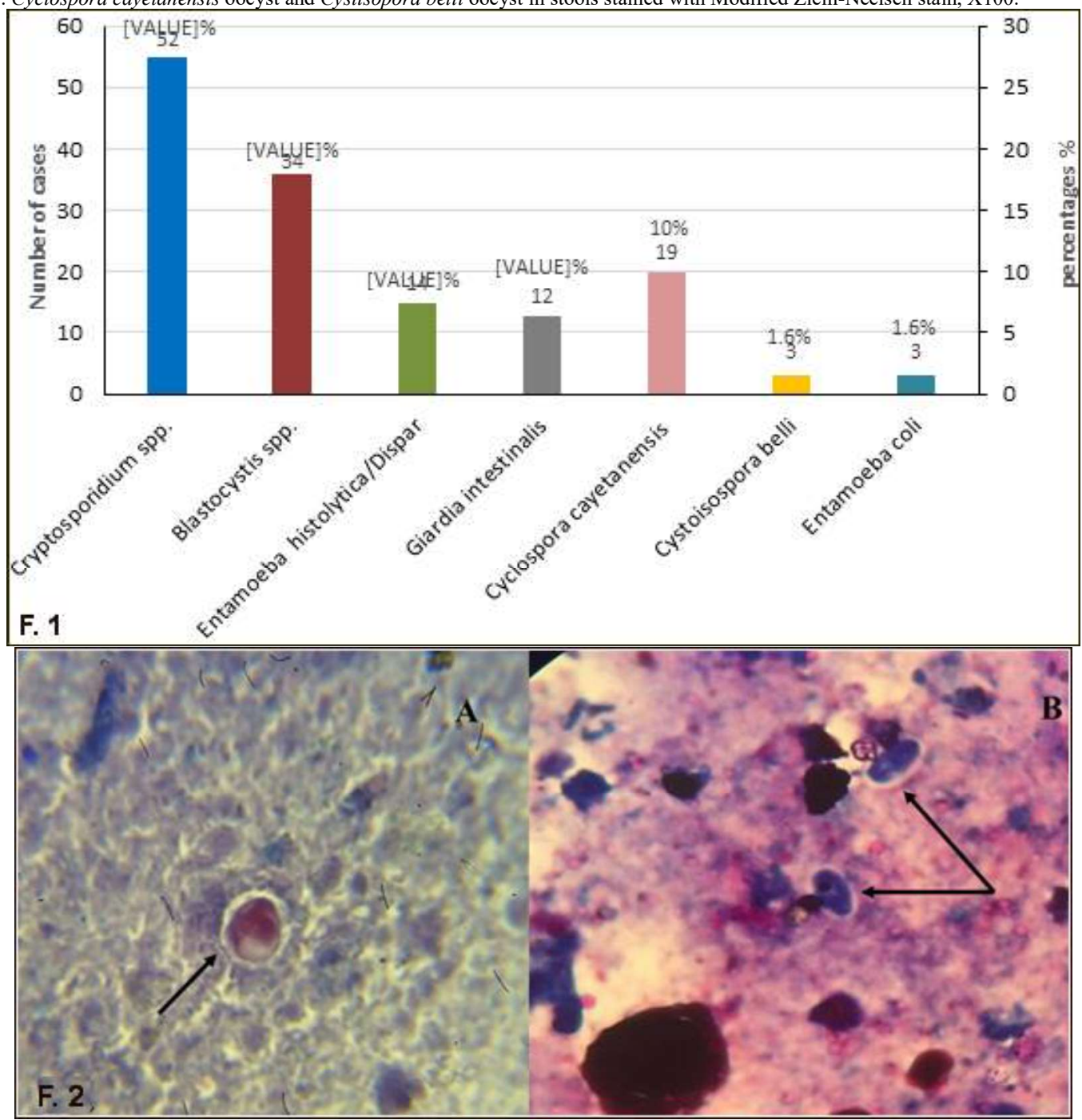